\title{
The Excretion of Insulin in Urine
}

\section{Correlation between Biological Activity and Immunoreactivity}

\author{
R. M. M. El-Allawy*, O. Sonne, J. Gliemann**, H. Ørskov and K. Johansen \\ Institute of Medical Physiology C, University of Copenhagen, the Second University Clinic of Internal Medicine, Kommunehospitalet, Århus \\ and Gentofte Amts Sygehus, Medical Department F, Hellerup, Denmark
}

\begin{abstract}
Summary. The concentration of biologically active insulin was measured by the isolated fat cell method in serum and urine from healthy subjects and compared with the concentration of immunoreactive insulin. In both urine and serum the values obtained by the two methods correlated closely. In addition, there was a close correlation between the concentration of biologically active and immunoreactive insulin in urine from maturity onset diabetics. Therefore, conclusions on the excretion in the urine and the urinary clearance of insulin, which are based on measurements of immunoreactive insulin, are also valid for biologically active insulin.
\end{abstract}

Key words: Urinary excretion of insulin, insulin-like activity, immunoreactive insulin, isolated fat cells, maturity onset diabetics.

A number of reports have been concerned with the excretion of immunoreactive insulin (IRI) in human urine [1-8] and it is generally agreed that only a small fraction of the insulin filtered in the glomeruli is excreted in the urine as IRI. The remainder is reabsorbed and degraded [2,4]. Rubenstein et al. [6] studied 33 healthy subjects and found relatively constant insulin clearances (range $0.23-0.87 \mathrm{ml} / \mathrm{min}$ ) under conditions where the concentration of insulin in plasma and the urinary flow varied widely. Ørskov and Johansen [7] found that the renal clearance for insulin during oral glucose tolerance tests repeated at weekly intervals varied with a factor of less than 1.7. These findings have led to the conclusion that the

\footnotetext{
* Holds a DANIDA Scholarship. Present address: Drug Research \& Control Centre, 6, Abou-Hazem St.-Pyramids Ave., Cairo, Egypt.

** To whom inquiries should be addressed.
}

concentration of insulin in the urine is a useful indicator of average serum insulin values over long periods of time.

Studies on some insulin degrading systems from liver and fat $[9,10]$ have shown that the rate of loss of the ability of insulin to bind to receptors exceeds the rate of loss of immunoreactivity. Since the receptor binding affinity appears closely correlated to the biological potency $[11,12]$ it seemed conceivable that the small fraction of the filtered immunoreactive insulin which appears in the urine, was not fully biologically potent. Little is known about insulin in urine assessed with biological techniques (for recent review see [13]). Liebermann [14] measured the insulin-like activity (ILA) in urine by the rat epididymal fat pad method and found a mean excretion rate of 50 $\mu \mathrm{U} / \mathrm{min}$ in healthy, fasting subjects. However, ILA measured in this way might to a large extent have represented factors other than insulin. We therefore decided to study insulin in urine from both healthy subjects and maturity onset diabetics in order to answer the question: Is the biological potency retained in the approximately $0.5 \%$ of the filtered insulin which appears in the urine as IRI? The ILA was measured by the isolated fat cell method $[15,16]$ both in the absence (total ILA) and in the presence (non-suppressible ILA) of an excess of insulin antibodies. Preliminary results have been presented elsewhere [17].

\section{Material and Methods}

\section{Subjects}

The healthy persons were aged 20-38 years and were within $10 \%$ of their ideal body weight. The maturity onset diabetics were of normal weight and aged 45-70 years. They were treated with tolbutamide and diet or with diet alone. 


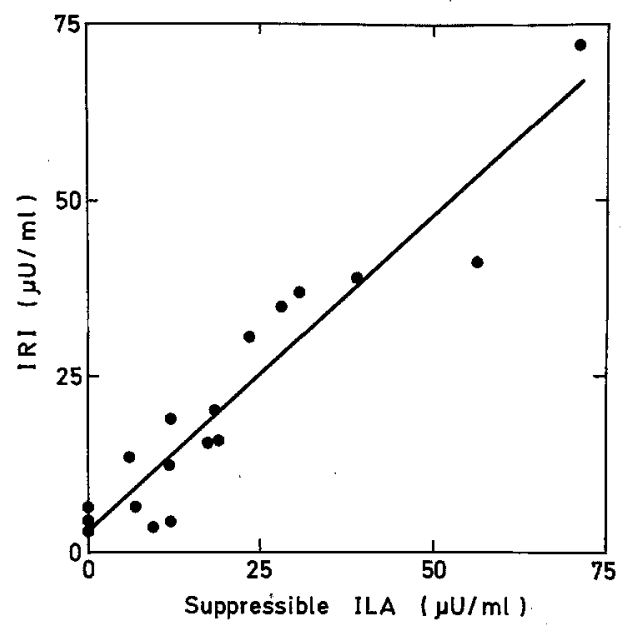

Fig. 1. Correlation between suppressible ILA and IRI in dialyzed serum from healthy subjects. The serum samples were prepared from blood taken $1 \mathrm{~h}$ after lunch. Suppressible ILA and IRI was measured as described in Materials and Methods. The correlation coefficient is $0.948, \mathrm{p}<0.001$

\section{Methods}

Urine was collected in $20 \mathrm{ml}$ precooled vials $\left(-20^{\circ} \mathrm{C}\right)$ which contained $20 \mathrm{mg}$ of bovine serum albumin (Sigma, fraction V). Thereby the temperature of the urine decreased immediately to about $10^{\circ} \mathrm{C}$. The urine samples were kept frozen at $-20^{\circ} \mathrm{C}$ for up to 4 weeks whereafter they were thawed and dialyzed for $24 \mathrm{~h}$ at $4^{\circ} \mathrm{C}$ against two changes of albumin-free buffer ( 800 $\mathrm{ml}$ ) of the same ionic composition as that used for incubation. Visking membrane $(10 \mathrm{~mm}$, Union Carbide Comp., New York) was used since it has previously been shown to be the least insulin permeable of several dialysis membranes, i. e. loss of immunoreactive insulin after $48 \mathrm{~h}$ averaged $32 \%$ [7].

Serum samples were prepared as previously described [18] and then subjected to dialysis. In addition, a solution of albumin $(10 \mathrm{mg} / \mathrm{ml}$ of water) was dialyzed together with the urine or serum samples; this was used for preparation of insulin standard solutions.

The biological activity was measured by the isolated fat cell method using the conversion of $\left[3-{ }^{3} \mathrm{H}\right]$ glucose to ${ }^{3} \mathrm{H}$-lipids as the parameter for insulin activity and extraction of the ${ }^{3} \mathrm{H}$-lipids by the addition of a toluene-based scintillation fluid directly to the incubation vials. The previously published procedure $[16,12]$ was modified as follows: The incubation medium was buffered with $25.0 \mathrm{mM} \mathrm{N}$-2-hydroxyethylpiperazine-N'-2-ethanesulfonic acid (HEPES). The exact composition of the medium is given elsewhere [19]. Each incubation vial contained either

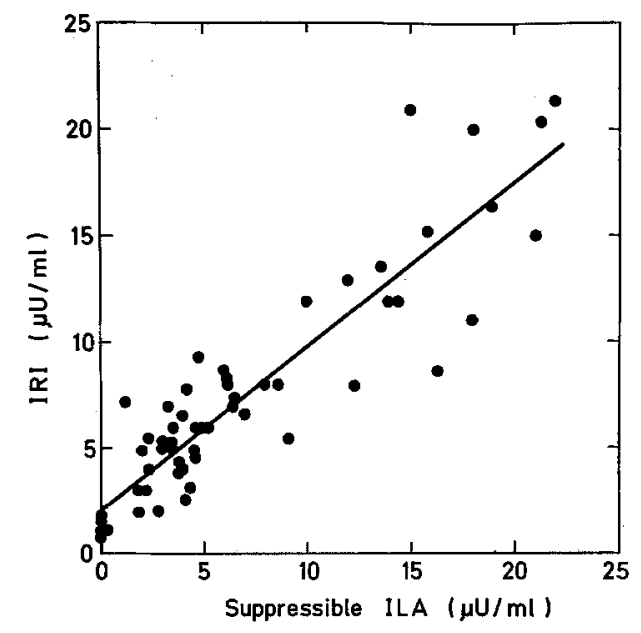

Fig. 2. Correlation between suppressible ILA and IRI in dialyzed urine from healthy subjects. In order to get a wide variation in the insulin concentrations, urine samples were taken both after overnight fast and $1 \mathrm{~h}$ after $50 \mathrm{~g}$ of oral glucose. Suppressible ILA and IRI was measured as described in Materials and Methods. The correlation coefficient is $0.901, p<0.001$

urine (final dilution of $1: 2$ ), serum (final dilution of $1: 7$ ) or pig insulin standard (NOVO, monocomponent, $28 \mathrm{U} / \mathrm{mg}$ ) in one of the following concentrations: $100,15,10,6.7,4.4,3.0,2.0,1.3$, or $0 \mu \mathrm{U} / \mathrm{ml}$. Each standard was assayed in 4 replicates and each serum or urine sample was assayed in 8 replicates: 4 in the absence and 4 in the presence of guinea pig antiinsulin serum sufficient to neutralize the effect of 100 $\mu U$ of the standard insulin. When ${ }^{125} \mathrm{I}$-labelled insulin was present in the incubation medium, the scintillation fluid was transferred to another counting vial in order to avoid interference with the counting of ${ }^{3} \mathrm{H}$ activity. The suppressible ILA was calculated as the difference between the total ILA (i. e. in the absence of anti-insulin) and the non-suppressible ILA (i. e. in the presence of anti-insulin). If no significant difference was obtained the suppressible ILA was recorded as zero.

The radioimmunoassay was carried out with a chromatographic wick technique as previously described for serum [20] and urine [7]. The insulin standard solutions were the same as those used in the fat cell assay. The anti-insulin did not discriminate between human insulin and human proinsulin.

\section{Evaluation of Methods}

The loss of porcine insulin after the dialysis was measured several times and ranged from 4-24\% (mean $13 \%$ ). In five experiments a trace amount of ${ }^{125} \mathrm{I}$ labelled insulin $(30 \mathrm{Ci} / \mathrm{g}$, final concentration 0.9 $\mu \mathrm{U} / \mathrm{ml}$ ) was added to dialyzed urine samples and the 
specific activity (i. e. ${ }^{125} \mathrm{I}$-activity per $\mu \mathrm{U}$ ) was found to remain constant $(97 \% \pm 3 \%, \mathrm{SD})$ after a second dialysis. Finally the recovery of biological activity of insulin added to dialyzed urine was indistinguishable from that of insulin added to buffer $(102 \% \pm 4 \%, S D$, $\mathrm{n}=5$ ).

It has previously been shown that the concentration of insulin in the urine can be measured accurately with the wick technique [7]. However, it is essential for both assay methods that the urine is cooled immediately and always handled in the cold. Urine samples which had been standing at room temperature for 30-60 min showed sometimes ILA values of more than $100 \mu \mathrm{U} / \mathrm{ml}$ and there was no effect of anti-insulin, i. e. the insulin concentration could not be measured by the fat cell method. We suspect that these effects are due to contamination with bacteria which produce proteases with insulin-like activity $[21,22]$. In such samples ${ }^{125} \mathrm{I}$-labelled insulin was also degraded, even at $4^{\circ} \mathrm{C}$, to an extent which made it impossible to measure the IRI.

\section{Results and Discussion}

It has previously been shown that the antibody-suppressible insulin-like activity (suppressible ILA) in native serum from healthy subjects corresponds closely to the immunoreactive insulin (IRI) [18]. The data shown in Figure 1 confirms this finding for dialyzed sera. The concentrations of non-suppressible ILA ranged from the equivalent of 10 to $35 \mu \mathrm{U}$ of insulin per $\mathrm{ml}$ and were not correlated with the values of suppressible ILA. Previous results have shown that the dose-response curve of total non-suppressible ILA in serum is not parallel to that of insulin [18] and the estimated potency concentrations of non-suppressible ILA are therefore only valid at the particular serum dilution of $1: 7$.

Figure 2 shows that a close correlation also exists between the suppressible ILA and the IRI in the dialyzed urine samples. It appears that the regression line intercepts with the ordinate at a value of about 2 $\mu \mathrm{U} / \mathrm{ml}$. Urine from healthy subjects contains proinsulin in a concentration of about $11 \%(\mathrm{w} / \mathrm{v})$ of that of insulin [23] and this could be the reason since proinsulin has a potency which is only a few per cent of that of insulin [24], whereas the anti-insulin used in the radioimmunoassay did not distinguish between insulin and proinsulin. In fact treatment of 7 urine samples with trypsin under conditions at which pro-insulin is converted to des-alanine B-30 insulin [24] caused a slight but significant increase in the suppressible ILA. Constan et al. [23] recently reported similar findings using specific radioimmunoassays to distinguish between insulin and proinsulin.

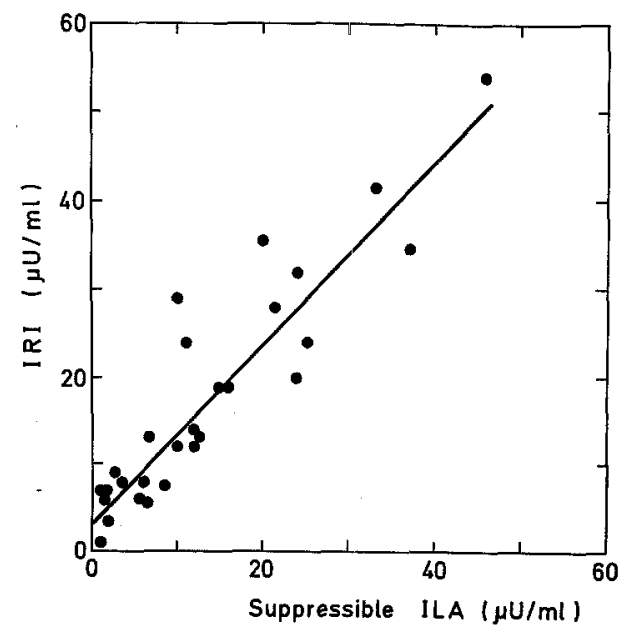

Fig. 3. Correlation between suppressible ILA and IRI in dialyzed urine from maturity onset diabetics. The experimental conditions were as described in the legend to Figure 2 . The correlation coefficient is $0.913, \mathrm{p}<0.001$

The non-suppressible ILA in the dialyzed urine ranged from $0-8 \mu \mathrm{U} / \mathrm{ml}$ (measured value times the dilution factor of 2). In most cases the concentration was $2-3 \mu \mathrm{U} / \mathrm{ml}$ ). However, as explained in Evaluation of Methods, non-suppressible ILA may appear in urine without representing physiological non-suppressible ILA excreted by the kidneys. The fact that the rate of excretion is low (or possibly unmeasurable with the present technique) is not surprising since it has been reported that most of the non-suppressible ILA in serum has a molecular weight of about 90,000 [25]. Furthermore, a carrier protein (molecular weight about 60,000 ) has been described for the small molecular weight non-suppressible ILA (NSILA-s) [26] and it is likely that more than $90 \%$ of the NSILA-s is present in serum in a bound state [27].

Figure 3 shows that the suppressible ILA and IRI are also closely correlated in urine from maturity onset diabetics. The values of non-suppressible ILA were not different from those found in urine from healthy persons.

The results strongly suggest that the suppressible ILA and IRI in serum and urine are the same entity, i. e. insulin. From this it follows that valid conclusions on the renal handling of insulin can be drawn from studies based on measurement of immunoreactive insulin in serum and urine.

\section{References}

1. Jørgensen, K. R.: Immunoassay of insulin in human urine. Acta endocr. (Kbh.) 51, 400-410 (1966)

2. Chamberlain, M. J., Stimmler, L.: The renal handling of insulin. J. clin. Invest. 46, 911-919 (1967) 
3. Rubenstein, A. H., Lowy, C., Fraser, T. R.: Radioimmunoassay of insulin in urine. Diabetologia 3, 453-459 (1967)

4. Rubenstein, A. H., Spitz, I.: Role of the kidney in insulin metabolism and excretion. Diabetes 17, 161-169 (1968)

5. Lowy, C., Schiff, D.: Urinary excretion of insulin in the healthy newborn. Lancet 1968 I, 225-227

6. Rubenstein, A. H., Lowy, C., Welborn, T. A., Fraser, T. R.: Urine insulin in normal subjects. Metabolism 16, 234-244 (1967)

7. Ørskov, H., Johansen, K.: Immunological measurements of urinary insulin for the evaluation of insulin production. Acta endocr. (Kbh.) 71, 697-708 (1972)

8. Johansen, K., Ørskov, H.: The stimulatory effect on insulin secretion in long-term tolbutamide treatment. Immunological determinations of urinary - and serum insulin. Acta endocr. (Kbh.) 71, 709-715 (1972)

9. Freychet, P., Kahn, R., Roth, J., Neville, D. M., Jr.: Insulin interactions with liver plasma membranes. Independence of binding of the hormone and its degradation. J. biol. Chem. 247 , 3953-3961 (1972)

10. Hammond, J. M., Jarett, L.: Insulin degradation by isolated fat cells and their subcellular fractions. Diabetes 24, 1011-1019 (1975)

11. Freychet, P., Brandenburg, D., Wollmer, A.: Receptor binding assay of chemically modified insulins. Comparison with in vitro and in vivo bioassays. Diabetologia 10, 1-5 (1974)

12. Gliemann, J., Gammeltoft, S.: The biological activity and the binding affinity of modified insulins determined on isolated rat fat cells. Diabetologia 10, 105-113 (1974)

13. Aun, F., Meguid, M. M., Soeldner, J. S., Stolf, N. A. G.: Urinary insulin levels in health and disease - a concise review. Postgrad. med. J. 51, 622-626 (1975)

14. Lieberman, L. L.: Insulin in urine. Lancet 1968 I, 148

15. Gliemann, J.: Assay of insulin-like activity by the isolated fat cell method. I. Factors influencing the response to crystallinc insulin. Diabetologia 3, 382-388 (1967)

16. Moody, A. J., Stan, M. A., Stan, M., Gliemann, J.: A simple free fat cell bioassay for insulin. Horm. Metab. Res. 6, 12-16 (1974)

17. El-Allawy, $\dot{R}$. M. M.: Chemical and biochemical studies on insulin action at the cellular level. $\mathrm{Ph}$. D. Thesis, Cairo University 1974
18. Gliemann, J.: Assay of insulin-like activity by the isolated fat cell method. II. The suppressible and non-suppressible insulinlike activity of serum. Diabetologia 3, 389-394 (1967)

19. Thorsteinsson, B., Gliemann, J., Vinten, J.: The content of water and potassium in fat cells. Biochim. biophys. Acta (Amst.) 428, 223-227 (1976)

20. Ørskov, H.: Wick-chromatography for the immunoassay of insulin. Scand. J. clin. Lab. Invest. 20, 297-304 (1967)

21. Kuo, J. F., Holmlund, C. E., Dill, I. K., Bohonos, N.: Insulinlike activity of a microbial protease on isolated fat cells. Arch. Biochem. Biophys. 117, 269-274 (1966)

22. El-Allawy, R. M. M., Gliemann, J.: Trypsin treatment of adipocytes: Effect on sensitivity to insulin. Biochim. biophys. Acta (Amst.) 273, 97-109 (1972)

23. Constan, L., Mako, M., Juhn, D., Rubenstein, A. H.: The excretion of proinsulin and insulin in urine. Diabetologia 11, 119-123 (1975)

24. Gliemann, J., Sørensen, H. H.: Assay of insulin-like activity by the isolated fat cell method. IV. The biological activity of proinsulin. Diabetologia 6, 499-504 (1970)

25. Poffenbarger, P. L.: The purification and partial characterization of an insulin-like protein from human serum. J. clin. Invest. 56, 1455-1463 (1975)

26. Zapf, J., Waldvogel, M., Froesch, E. R.: Binding of nonsupressible insulinlike activity to human serum. Arch. Biochem. Biophys. 168, 638-645 (1975)

27. Megyesi, K., Kahn, C. R., Roth, J., Gorden, P.: Circulating NSILA-s in man: Preliminary studies of stimuli in vivo and of binding to plasma components. J. clin. Endocr. 41, 475-484 (1975)

Received: May 10, 1976, and in revised form: July 5, 1976

Dr. J. Gliemann

Institute of Medical Physiology C

Univ. of Copenhagen

71 Radmandsgade

DK-2200 Copenhagen $N$

Denmark 